13.1

\title{
Осаждение фторполимерных покрытий на вращающиеся цилиндрические поверхности методом химического осаждения из газовой фазы, активированной горячей нитью
}

\author{
(C) А.И. Сафонов ${ }^{1}$, С.В. Старинский ${ }^{1}$, В.С. Суляева ${ }^{2}$ \\ ${ }^{1}$ Институт теплофизики им. С.С. Кутателадзе СО РАН, Новосибирск, Россия \\ ${ }^{2}$ Институт неорганической химии им. А.В. Николаева СО РАН, Новосибирск, Россия \\ E-mail: safonov@itp.nsc.ru
}

Поступило в Редакцию 29 июля 2020г.

В окончательной редакции 8 сентября 2020 г.

Принято к публикации 13 ноября 2020 г.

Метод химического осаждения из газовой фазы, активированной горячей нитью (hot wire chemical vapor deposition), адаптирован для осаждения фторполимерных покрытий на вращающиеся цилиндрические поверхности малого радиуса (менее $20 \mathrm{~mm}$ ). Исследовано влияние частоты вращения поверхности на строение осаждающегося на ней тонкого фторполимерного покрытия. Обнаружено существенное изменение морфологии формируемого фторполимерного покрытия в зависимости от частоты вращения цилиндрической поверхности. Определен дополнительный параметр (частота вращения цилиндрической поверхности), варьирование которого позволяет изменять строение формируемого фторполимерного покрытия в процессе осаждения.

Ключевые слова: фторполимер, осаждение, вращающиеся поверхности, HW CVD.

DOI: 10.21883/PJTF.2021.04.50647.18488

Покрытия из фторполимера благодаря комбинации их уникальных свойств используются в широком диапазоне прикладных задач. Так, фторполимерные покрытия весьма перспективны для применения в задачах интенсификации теплообмена $[1,2]$ вследствие выраженной гидрофобности, играющей важную роль при фазовых превращениях $[3,4]$. Свойства смачивания водой материала определяются, как правило, двумя основными факторами: микрорельефом поверхности и ее свободной энергией [5]. Основными способами получения тонких пленок фторполимеров с различным строением являются методы физического (physical vapor deposition, PVD) и химического осаждения из газовой фазы (chemical vapor deposition, CVD) [6-10]. Эти методы, как правило, ориентированы на осаждение покрытий на гладкие и равномерные поверхности, в то время как большинство современных теплообменных устройств состоит из металлических цилиндрических элементов малого радиуса. Поэтому адаптация этих методов для создания покрытий на таких поверхностях является актуальнейшей задачей.

В настоящей работе проведена адаптация одного из CVD-методов для осаждения фторполимерных покрытий на цилиндрическую поверхность малого радиуса. Для нанесения фторполимерного покрытия был использован метод HW CVD (hot wire chemical vapor deposition) $[11,12]$. Суть метода заключается в активации газа-прекурсора горячим проволочным катализатором в неглубоком вакууме. Поток активируемого газа движется к поверхности образца, где происходит осаждение покрытия путем полимеризации активных частиц. Изменение параметров процесса осаждения приводит к изменению поверхностного строения покрытия [13]. В настоящей работе было использовано вращение цилиндрического образца во время процесса осаждения, что позволило избежать неравномерности толщины покрытия, характерной для осаждения из газовой фазы [14].

Экспериментальная установка и схема метода HW CVD подробно представлены в работе [13]. В вакуумной камере установки был размещен механизм, позволяющий вращать цилиндрические образцы малого диаметра (трубки, стержни). Диаметр образцов может регулироваться в диапазоне от 1 до $20 \mathrm{~mm}$. В экспериментах изменяемым параметром была частота вращения образца, она составляла 1, 10, $100 \mathrm{rpm}$. Остальные параметры процесса осаждения были стабилизированы. Газпрекурсор $\mathrm{C}_{3} \mathrm{~F}_{6} \mathrm{O}$ - окись гексафторпропилена (ОГФП) подавался в камеру с расходом $100 \mathrm{sccm}$ через регуляторы расхода в газовый распределитель, расположенный в верхней части камеры над активатором. Поток газа прекурсора активировался сеткой, изготовленной из горячей нихромовой нити диаметром $0.5 \mathrm{~mm}$. Температура нити поддерживалась равной $770^{\circ} \mathrm{C}$ и контролировалась по электрическому сопротивлению и контактно двумя хромель-алюмелевыми термопарами. Давление газа прекурсора в камере регулировалось открытием сильфонного затвора, во время процесса осаждения оно составляло $67 \mathrm{~Pa}$. Под сеткой активатора на расстоянии $70 \mathrm{~mm}$ располагался держатель образцов. Держатель позволяет вращать образцы с управляемой частотой в диапазоне от 0.1 до $200 \mathrm{rpm}$. Образцами служили цилиндрические трубки диаметром $3 \mathrm{~mm}$ и длиной $20 \mathrm{~mm}$, изготовленные из нержавеющей стали $(12 \mathrm{X} 18 \mathrm{H} 10 \mathrm{~T})$. Морфология 

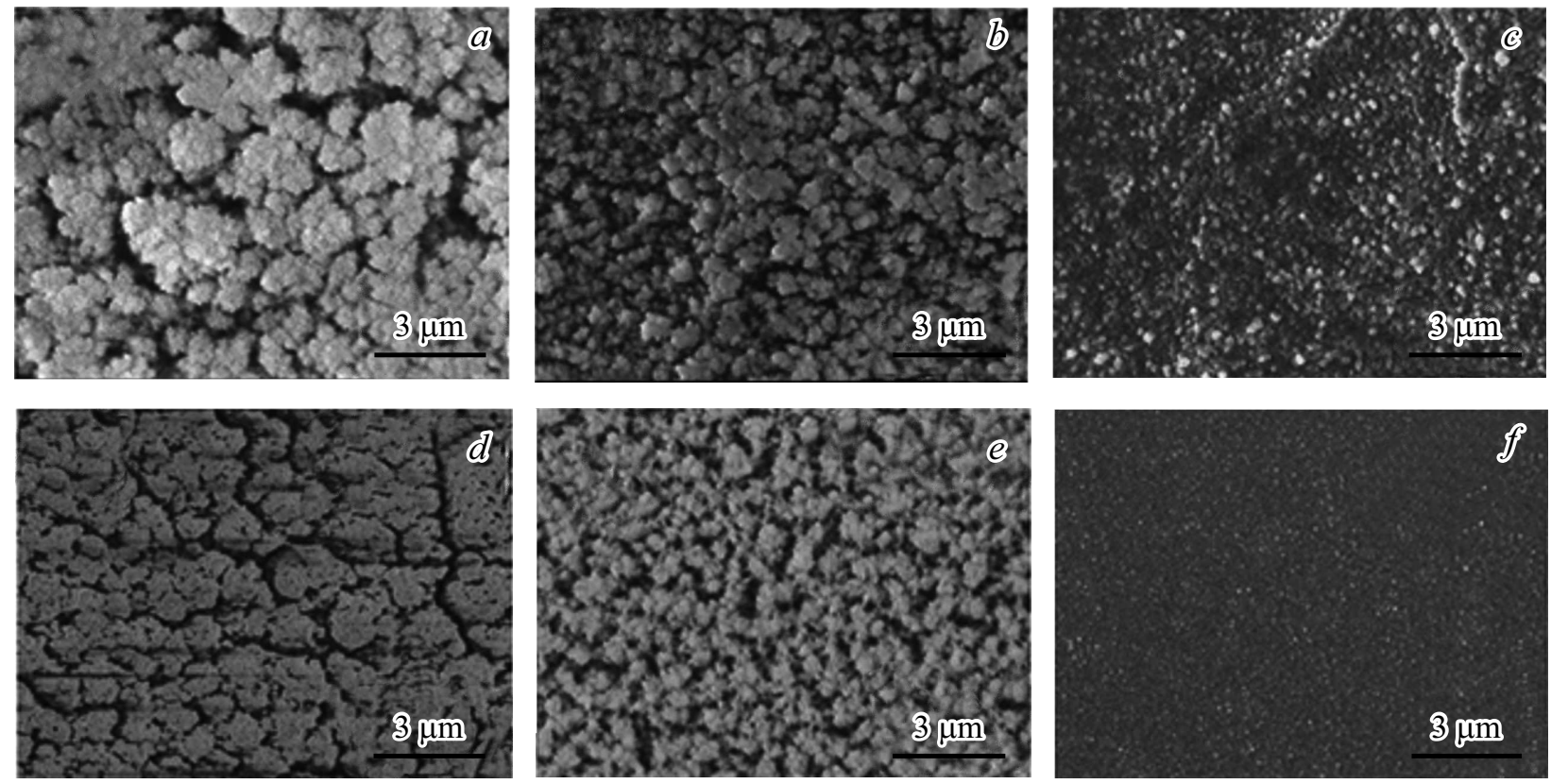

Морфология фторполимерных покрытий, полученных при различной частоте вращения трубки ( $a-1 \mathrm{rpm}, b-10 \mathrm{rpm}$, $c-100 \mathrm{rpm})$ и различной температуре активатора $\left(d-850^{\circ} \mathrm{C}, e-840^{\circ} \mathrm{C}, f-700^{\circ} \mathrm{C}\right.$, адаптировано из работы [13]).

полученных покрытий изучалась методом сканирующей электронной микроскопии на приборе JEOL JSM 6700F.

На рисунке представлена морфология полученных покрытий. В ходе экспериментов было установлено, что морфология покрытия критическим образом зависит от частоты вращения цилиндрических образцов $($ см. рисунок, $a-c)$. Характер изменения морфологии поверхности покрытия с увеличением частоты вращения образцов идентичен снижению температуры активатора при осаждении на неподвижную поверхность (см. рисунок, $d-f$ ) [13]. Сегодня наиболее общая точка зрения на кинетику формирования фторполимерного покрытия при осаждении методом HW CVD предполагает, что в реакции полимеризации активные центры роста представляют собой радикалы. Предполагается, что газ-прекурсор ОГФП при контакте с разогретым активатором распадается термически и/или каталитически по реакции $\mathrm{C}_{3} \mathrm{~F}_{6} \mathrm{O} \rightarrow: \mathrm{CF}_{2}+\mathrm{C}_{2} \mathrm{~F}_{4} \mathrm{O}$ [10]. Далее продукты разложения двигаются к поверхности осаждения, где свободные радикалы (: $\left.\mathrm{CF}_{2}\right)$ взаимодействуют с поверхностью и происходит зарождение и рост полимерных цепочек, формируется фторполимерное покрытие. Строение и свойства покрытия определяются динамикой образования полимерных связей, которые в значительной степени зависят от интенсивности потока радикалов на поверхность образца. В процессе движения радикалы могут также сталкиваться между собой и рекомбинировать по реакции $2\left(: \mathrm{CF}_{2}\right) \rightarrow \mathrm{C}_{2} \mathrm{~F}_{4}$ [10]. Как было показано в работе [13], поток радикалов может контролироваться температурой нити активатора и газодинамическими условиями процесса осаждения, т.е. с уменьшением температуры активатора формируется и достигает поверхности осаждения меньшее число радикалов. Благодаря низкому количеству радикалов при полимеризации формируются более плотные покрытия. При большем потоке радикалов полимерные цепи формируются хаотично, что приводит к осаждению покрытий с развитым строением (дендриты, пористые покрытия, порошок), что можно наблюдать на рисунке (части $d, e$ ).

Поскольку тенденция изменения морфологии при увеличении частоты вращения цилиндрического образца такая же, как при изменении температуры, был сделан вывод, что при высоких частотах вращения поверхности в единицу времени достигает меньшее число радикалов. Мы полагаем, что это уменьшение числа радикалов может быть объяснено газодинамическими процессами в пограничном слое, приводящими к оттеснению радикалов от поверхности и их рекомбинации. Тем самым значительно снижается взаимодействие радикалов с поверхностью, что существенно влияет на строение формируемого фторполимерного покрытия. Например, к таким процессам можно отнести изменения полей давления и скорости вблизи поверхности образца, как это было показано для случая вращения цилиндра в разреженном газе [15].

Таким образом, показано, что при осаждении методом HW CVD на вращающиеся цилиндрические поверхности малого радиуса морфология фторполимерного покрытия существенно изменяется и зависит от частоты вращения поверхности. Обнаружено подобие влияния температуры нити активатора и частоты вращения цилиндра на морфологию получаемого покрытия. Выдвинуто предположение, что изменение морфологии 
вызвано снижением количества свободных радикалов, достигающих поверхности образца. Это снижение объясняется изменением газодинамических параметров в пограничном слое с увеличением скорости набегающего потока, вызванным вращением образца, что приводит к рекомбинации радикалов в потоке. Таким образом, определен дополнительный параметр (частота вращения цилиндрической поверхности), варьирование которого позволяет изменять строение формируемого фторполимерного покрытия в процессе осаждения. Полученные результаты могут быть обобщены и на ряд других методов осаждения из газовой фазы.

\section{Финансирование работы}

Работа выполнена при финансовой поддержке гранта Российского научного фонда (проект № 18-79-10119).

\section{Конфликт интересов}

Авторы заявляют, что у них нет конфликта интересов.

\section{Список литературы}

[1] T. Allred, J. Weibel, S. Garimella, Phys. Rev. Lett., 120, 174501 (2018). https://doi.org/10.1103/PhysRevLett.1204501

[2] Y. Li, K. Zhang, M.-C. Lu, C. Duan, Int. J. Heat Mass Transfer, 99, 521 (2016). https://doi.org/10.1016/j.jheatmasstransfer.2016.03.098

[3] И.И. Гогонин, Теплофизика и аэромеханика, 17 (2), 261 (2010). https://www.sibran.ru/upload/iblock/c61/c6187 e3b5ce5c5fe0854eba312a4eb93.pdf

[4] А.С. Суртаев, В.С. Сердюков, А.Н. Павленко, Рос. нанотехнологии, 11 (11-12), 18 (2016).

[5] Л.Б. Бойнович, А.М. Емельяненко, Успехи химии, 77 (7), 619 (2008). https://www.uspkhim.ru/php/paper _rus.phtml?journal_id=rc\&paper_id=3775

[6] T. Smausz, B. Hopp, N. Kresz, J. Phys. D: Appl. Phys., 35, 1859 (2002). https://iopscience.iop.org/article/10.1088/0022$3727 / 35 / 15 / 307 /$ pdf

[7] A. Satyaprasad, V. Jain, S.K. Nema, Appl. Surf. Sci., 253, 5462 (2007). https://doi.org/10.1016/j.apsusc.2006.12.085

[8] B. Finke, H. Testrich, H. Rebl, U. Walschus, M. Schlosser, C. Zietz, S. Staehlke, J.B. Nebe, K.D. Weltmann, J. Meichsner, M. Polak, J. Phys. D: Appl. Phys., 49, 234002 (2016). https://doi.org/10.1088/0022-3727/49/23/234002

[9] T. Oya, E. Kusano, Vacuum, 83, 564 (2009). https://doi.org/10.1016/j.vacuum.2008.04.040

[10] K.K.S. Lau, J.A. Caulfield, K.K. Gleason, Chem. Mater., 12, 3032 (2000). https://doi.org/10.1021/cm000499w

[11] K.K.S. Lau, H.G. Pryce Lewis, S.J. Limb, M.C. Kwan, K.K. Gleason, Thin Solid Films, 395, 288 (2001) https://doi.org/10.1016/S0040-6090(01)01287-1

[12] A.C. Rastogi, S.B. Desu, Polymer, 46, 3440 (2005). https://doi.org/10.1016/j.polymer.2004.10.082

[13] A.I. Safonov, V.S. Sulyaeva, E.Ya. Gatapova, S.V. Starinskiy, N.I. Timoshenko, O.A. Kabov, Thin Solid Films, 653, 165 (2018). https://doi.org/10.1016/j.tsf.2018.03.015
[14] D.D. Hass, Y. Marciano, H.N.G. Wadley, Surf. Coat. Technol., 185, 283 (2004). https://doi.org/10.1016/j.surfcoat.2003.12.027

[15] J. Benzi, X.-J. Gu, R.W. Barber, D.R. Emerson, AIAA J., 54, 670 (2016). https://doi.org/10.2514/1.J054782 